\section{Thinking about cloning}

Dolly has certainly had her day. But when the media dust has cleared, and the solemn-faced social scientists and molecular biologists intoning from the apocalyptic literature have faded from the television screens, and the terrible sheep jokes and clone puns have been irretrievably distributed across the web of long-term memory, some real issues will remain.

Dolly represents breakthrough science to the extent that she will provide many wonderful insights into cellular and developmental processes, and it is even possible that cloning transgenic animals will be a boon for barnyard biotechnology, as the news story on p. 306 describes. But as Jonathan MacQuitty points out in his commentary (p. 294), Dolly's greatest contribution may be, not to the development of expensive herds of painstakingly cloned animals, but to technologies and medical applications that can be brought into and controlled in vitro, not in vivo. Yet if Dolly's scientific future is still somewhat ambiguous, not so her role in catalyzing an enormous hue and cry about the imminent cloning of human beings.

Beyond mutterings about immortality (this notion of human cloning contains the conceit of an ultimate genetic determinism, that somehow consciousness can be clonally propagated), there are the apparently more realistic discussions about infertility. But isn't in vitro fertilization, which is wildly expensive, overhyped, and often unsuccessful, the source of enough lessons in this regard?

Questions about human dignity and the sacredness of human life did not originate with Dolly. We are already traversing the slippery slope of the commoditization of human beings and their biological parts-from "simpler" commodities of blood and skin and organs to the more complex transactions of babies made to donate marrow to older ailing siblings, and grandmothers giving birth to their grandchildren. These are real issues that require our ethical, societal, and scientific attentions. And their discussion is not helped by reflexive hyperactivity, replete with calls for banning something that it is far from clear anyone could, or would, want to do. A carefully proscribed moratorium while we catch our collective breath, and wait for corroborating evidence that Dolly is indeed what she is touted to be, is both prudent and response enough.

\section{Thanks for the advice}

Bioethics and bioscience advisory bodies have a propensity to generate similar committees. It is a process akin to the budding of yeasts. Thus, in the UK, the Nuffield Council on Bioethics begat the Human Genetics Advisory Commission, which begat the Gene Therapy Advisory Committee and the Advisory Committee on Genetic Testing, which has just set up a group to explore genetics in insurance and employment.

In the US, the NIH/DOE Working Group on the Ethical, Legal, and Social Implications of Human Genome Research created the Task Force on Genetic Testing, which just recently proposed the formation of the National Genetics Board to provide expert guidance to those reviewing the validity of genetic tests. At the same time, two separate genetic subcommittees may be established to advise the US Food and Drug Administration, on the one hand, and the Clinical Laboratory Improvement Advisory Committee of the Health Care Financing Administration, on the other. To be fair, the task force itself is about to disband: More programmed cell death, perhaps, than asymmetric binary fission.

But, to paraphrase Oscar Wilde, it seems there is one thing worse than having lots of advisory groups, and that is not having them. Japan has no committees advising government bodies on gene ethics. The Japanese Society of Obstetrics and Gynecology was, until recently, preparing guidelines on the ethical implications of prenatal screening, but it shelved them (following a protest from patient advocacy group, incidentally). This was not a positive turn of events. Genetic screening now joins the list of biomedical advances about which little or no debate has been held in Japan. Other "controversial" issues hardly discussed include smoking-related disease and a definition of brain death. The consequences of this silence are that it is still illegal to levy additional premiums when insuring smokers' lives, and that organ transplantation of any kind is virtually unheard of.

In this light, committees and working parties don't seem so bad. As long as they take the debate forward, it may indeed be progress for genetics advisory groups to metamorphose. When the consequences of not having a debate are stasis, the consequences of not briskly reaching a conclusion seem less exasperating.

\title{
Mapping a drug development revolution
}

Whether you call it "directed molecular evolution," "in vitro genetics," "systematic evolution of ligands by exponential enrichment (SELEX)," "epitope libraries," "unnatural evolution," "evolution in a test tube," "irrational drug design," or simply "combinatorial chemistry," if you are in a biotechnology company, it is likely that it is part of your drug discovery and development program. If not, it will be: At present, over 180 companies list combinatorial chemistry as part of theirs, with deals valued over $\$ 2.6$ billion-and growing. To get a sense of how important combinatorial chemistry is to the future of drug development, we put together a map of the companies involved and their deals (see pullout).

The pervasiveness of the technology across both pharmaceutical and biotechnology companies is striking. Larry Gold and Joe Alper from NeXstar explain why (p. 297): Whereas genomics promises to deliver new targets, these targets may turn out to be blind alleys with respect to products. Combinatorial chemistry, argue the authors ". . provides the means to bypass genomics and proceed directly to targets of biological relevance without needing to know what gene is involved."

While the potential power of this approach is undeniable, the kinks have not yet been worked out: Generating huge number of compounds creates a screening bottleneck itself. This problem has created a niche for startups to generate smaller combinatorial libraries that speak the language of the medicinal chemist-using templates based on existing pharmaceutical chemistries (see p. 328).

Finally, in this issue we launch a new column in the Resources section called "Industry Trends." In the first article, Aris Persidis analyzes the combinatorial chemistry industry (p. 391) and finds that, despite the vast amount of money that has poured into combinatorial chemistry, the long-term viability of the technology as a business remains to be seen. The speed with which combinatorial chemistry based drug leads get into clinical trials-and onto the market-will determine whether these methods can legitimately be declared responsible for sparking a drug-development revolution. 